\title{
Distinguishing between anomalous origin of the left coronary artery from the pulmonary trunk and dilated cardiomyopathy: role of echocardiographic measurement of the right coronary artery diameter
}

\author{
KAZUYUKI KOIKE, NORMAN N MUSEWE, JEFFREY F SMALLHORN, \\ ROBERT M FREEDOM
}

From the Hospital for Sick Children, Division of Cardiology, Department of Pediatrics, University of Toronto, Canada

SUMMARY Patients with anomalous origin of the left coronary artery from the pulmonary trunk usually have a large right coronary artery. This study examines the diagnostic value of measuring: the diameter of the right coronary artery by echocardiography in distinguishing between this lesion and other causes of dilated cardiomyopathy. The diameter of the right coronary artery and the right coronary artery/aorta ratio were measured in the parasternal short axis view in 40 controls, $1 \frac{10}{\circ}$ patients with dilated cardiomyopathy, and 10 with anomalous origin of the left coronary artery from the pulmonary trunk. In the controls, the diameter of the right coronary artery increased with age, but the right coronary artery/aorta ratio remained constant. In the control group the $95 \%$ upper limits of prediction for right coronary artery diameter were $1.6 \mathrm{~mm}$ for one month of age $1.8 \mathrm{~mm}$ for three months, $2.0 \mathrm{~mm}$ for one year, $2.2 \mathrm{~mm}$ for two years, $2.4 \mathrm{~mm}$ for three years $2.6 \mathrm{~mm}$ for four years, $2.7 \mathrm{~mm}$ for six years, $3.0 \mathrm{~mm}$ for eight years, and $3.2 \mathrm{~mm}$ for 10 years; and for right coronary/aorta ratios the limits were 0.17 for one month to one year, 0.18 for one to sid years, 0.19 for six to 10 years, and 0.20 for more than 10 years. All patients with dilated cardiomyopathy had normal right coronary artery diameters and right coronary artery/aorta ratios $(0 \cdot 10-0 \cdot 13)$. Those patients with anomalous origin of the left coronary artery from the pulmonary trunk had larger than normal right coronary artery diameter and a significant increase in the righ coronary artery/aorta ratio $(0 \cdot 21-0 \cdot 29)$.

The presence of an anomalous left coronary artery was likely if the diameter of the right coronary artery or the right coronary artery/aorta ratio was larger than the normal $95 \%$ limits of prediction:

Anomalous origin of the left coronary artery from the pulmonary trunk is one of the rare causes of dilated cardiomyopathy in infants and children. ${ }^{1}$ Because an operation may give better results than medical treatment, early recognition and differentiation from other causes of dilated cardiomyopathy may be important in preventing the development of extensive myocardial damage. ${ }^{2-4}$ Recent advances in cross sectional echocardiography permit the diagnosis to be made non-invasively'; however, it may not always be possible to image the origin of the left coronary

Requests for reprints to Dr Jeffrey F Smallhorn, Division of Cardiology, The Hospital for Sick Children, 555 University Avenue, Toronto, Ontario, Canada M5G 1 X8.

Accepted for publication 5 July 1988 artery from the pulmonary trunk. ${ }^{6}$ Similarly, con $\mathrm{g}$ fusion with the transverse sinus has given rise to falso positives. ${ }^{7}$ On the other hand, the right coronare. artery is usually dilated and tortuous in anomolous origin of the left coronary artery from the pulmonary trunk. ${ }^{89}$ This report assesses the role of measuremens of diameter of the main right coronary artery by cross sectional echocardiography in distinguishin between this lesion and other forms of dilated cardiomyopathy.

\section{Patients and methods}

We studied 10 patients with anomalous origin of the left coronary artery from the pulmonary trunk (age $\$$ 3-79 months, median 7.5 months) (table 1), 11 with 
Table 1 Patients with anomalous origin of the left coronary artery from the pulmonary trunk

\begin{tabular}{|c|c|c|c|c|}
\hline No & Age (mnth) & $R C A(\mathrm{~mm})$ & $A O(\mathrm{~mm})$ & $R C A / A O$ \\
\hline $\begin{array}{r}1 \\
2 \\
3 \\
4 \\
5 \\
6 \\
7 \\
8 \\
9 \\
10\end{array}$ & $\begin{array}{r}3 \\
3 \\
4 \\
7 \\
8 \\
9 \\
15 \\
55 \\
70 \\
79\end{array}$ & $\begin{array}{l}2 \cdot 6 \\
2 \cdot 2 \\
2.3 \\
2 \cdot 2 \\
2.0 \\
3.0 \\
3.5 \\
3.6 \\
4.4 \\
3.9\end{array}$ & $\begin{array}{r}9.0 \\
9.0 \\
9.5 \\
10.0 \\
10.0 \\
11.0 \\
12.0 \\
17.5 \\
15.5 \\
18.0\end{array}$ & $\begin{array}{l}0.29 \\
0.26 \\
0.24 \\
0.22 \\
0.20 \\
0.27 \\
0.29 \\
0.21 \\
0.28 \\
0.22\end{array}$ \\
\hline
\end{tabular}

AO, diameter of the aortic root; RCA, diameter of the right coronary artery; RCA/AO, ratio of right coronary artery to aorta.

dilated cardiomyopathy of another cause (aged 2-113 months, median 7 months) (table 2 ), and 40 controls (aged 1-123 months, median 29.5 months). The cause of the dilated cardiomyopathy was endocardial fibroelastosis in eight patients and idiopathic cardiomyopathy in three patients.
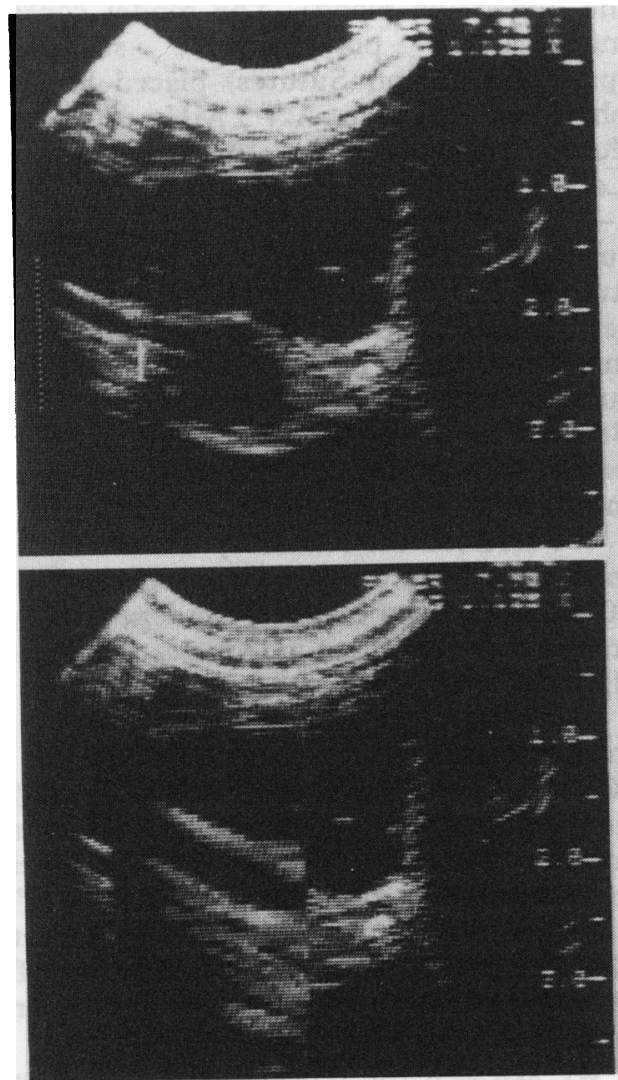

Table 2 Patients with dilated cardiomyopathy

\begin{tabular}{|c|c|c|c|c|c|}
\hline No & Age (mnth) & $R C A(\mathrm{~mm})$ & $A O(\mathrm{~mm})$ & $R C A / A O$ & Aetiology \\
\hline $\begin{array}{r}1 \\
2 \\
3 \\
4 \\
5 \\
6 \\
7 \\
8 \\
9 \\
10 \\
11\end{array}$ & $\begin{array}{r}2 \\
3 \\
4 \\
6 \\
6 \\
7 \\
7 \\
13 \\
44 \\
54 \\
113\end{array}$ & $\begin{array}{l}0.9 \\
1.1 \\
1.1 \\
1.1 \\
1.2 \\
1.2 \\
1.1 \\
1.2 \\
1.7 \\
1.6 \\
1.9\end{array}$ & $\begin{array}{r}9.0 \\
9.0 \\
9.5 \\
10.0 \\
10.0 \\
10.0 \\
10.0 \\
12.0 \\
13.0 \\
14.0 \\
17.0\end{array}$ & $\begin{array}{l}0 \cdot 10 \\
0 \cdot 12 \\
0 \cdot 12 \\
0.11 \\
0.12 \\
0.12 \\
0 \cdot 11 \\
0 \cdot 10 \\
0.13 \\
0 \cdot 11 \\
0 \cdot 11\end{array}$ & $\begin{array}{l}\text { EFE } \\
\text { EFE } \\
\text { EFE } \\
\text { EFE } \\
\text { EFE } \\
\text { EFE } \\
\text { EFE } \\
\text { EFE } \\
\text { ICM } \\
\text { ICM } \\
\text { ICM }\end{array}$ \\
\hline
\end{tabular}

AO, diameter of the aortic root; EFE, endocardial fibroelastosis; ICM, idiopathic cardiomyopathy; RCA, diameter of the right coronary artery; RCA/AO, ratio of right coronary artery to aorta.

We reviewed videotapes recorded from a standard approach with a $7.5 \mathrm{MHz}$ transducer. We used a parasternal short axis view at the level of the right coronary artery for all patients and controls. The vessel was measured between 0.5 and $1 \mathrm{~cm}$ from the ostium. This enabled the diameter to be assessed in

Fig 1 Echocardiographic method for measurement of right coronary artery (RCA) and aortic diameters. Measurement line is aligned with the axial beam. Right coronary artery is measured in a magnified image by PGS (Professional Graphic System, Symtec). 


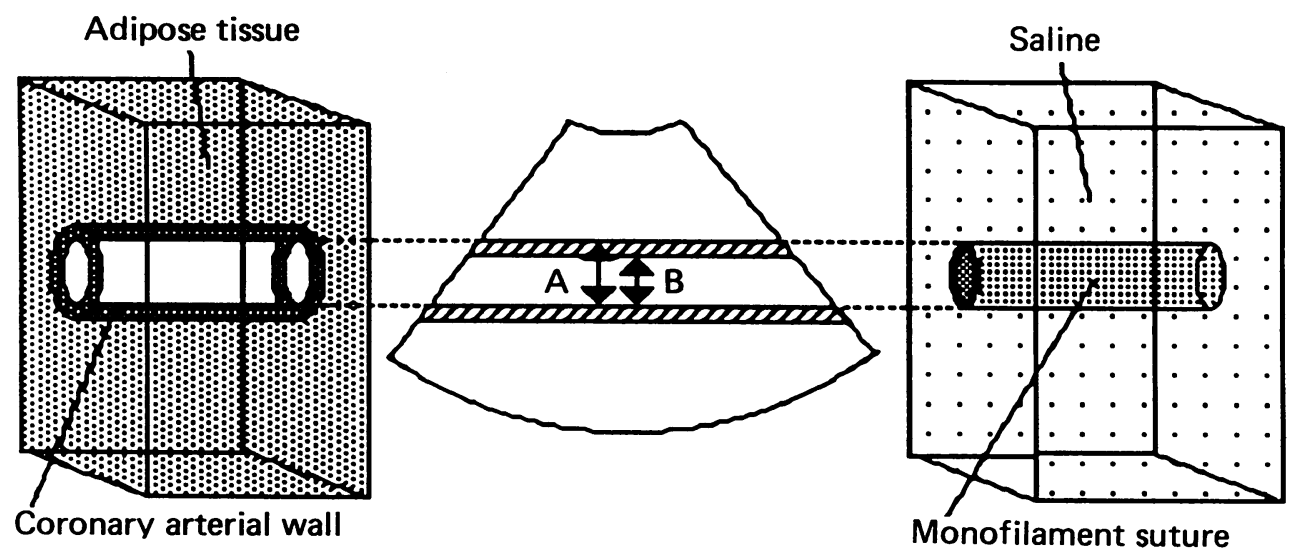

Anatomy

Echo

Phantom

Fig 2 Custom phantom model for assessing the accuracy of the measurement of the coronary artery. A, leading edge method; $B$, internal measurement. See text for explanation.

the axial plane of the ultrasound beam. The distance between the transducer and right coronary artery varied from $1 \mathrm{~cm}$ to $3 \mathrm{~cm}$, depending on the age of the patient. Because the echo impedances of the coronary artery wall and surrounding adipose tissue are similar, we measured the internal dimensions of the coronary artery. We used a computer assisted video image digitising system (Professional Graphics System, Symtec), which enabled us to measure the distance directly on the video monitor from a magnified image. A part of the echocardiographic image was magnified twice so that one pixel measured $0 \cdot 1-$ $0.3 \mathrm{~m}$ on the video screen (fig 1 ). The internal diameter of the aorta was measured on the same view in the axial plane.

A custom made phantom model was created to assess the axial resolution of our equipment (Advanced Technology Laboratories, Ultramark 8) at depths varying from $1 \mathrm{~cm}$ to $3 \mathrm{~cm}$ with a $7.5 \mathrm{MHz}$ transducer (fig 2). Because the echo impedances of the coronary artery wall and surrounding adipose tissue are similar echoes are reflected effectively only at the interfaces between coronary arterial walls and

Table 3 Diameter of the surgical sutures*

\begin{tabular}{llll}
\hline & & \multicolumn{2}{l}{ Limits on average diameter $(\mathrm{mm})$} \\
\cline { 3 - 4 } USP size & Metric size (mm) & Minimum & Maximum \\
\hline 1 & 4 & 0.40 & 0.499 \\
0 & 3.5 & 0.35 & 0.399 \\
$2-0$ & 3 & 0.30 & 0.339 \\
$3-0$ & 2 & 0.20 & 0.249 \\
$4-0$ & 1.5 & 0.15 & 0.199 \\
\hline
\end{tabular}

^United States Pharmacopeia XXI, p 1009. the lumen (or blood). The model consisted of amonofilament polypropylene surgical sutureo (prolene, Ethicon Sutures) placed horizontally in ${ }^{\circ}$ physiological saline. A 7.5 MHz ultrasound transducer (Access C, Advanced Technology Laboratories, $6.4 \mathrm{~mm}$ in diameter, $2 \mathrm{~cm}$ focus point, $1-4 \mathrm{~cm}$ focus zone) was placed $1-3 \mathrm{~cm}$ above the $\frac{0}{\circ}$ suture. The cross sectional image showed the long- $\propto$ itudinal axis of the suture. We used minimal gain $\vec{\circ}$ settings to exclude reverberation echoes. We deter- 3 mined the limits of axial resolution by examining sutures that varied in size from 1 to 4-0 USP (United? States Pharmacopeia) (table 3). Two horizontal parallel lines were derived from the upper and lower interfaces of the suture.

We assessed the reliability of the vessel diameter 3 . measurement by cross sectional echocardiography in 20 controls. Two observers independently selected frames from recorded videotapes and measured theo right coronary artery and aorta twice.

\section{STATISTICAL ANALYSIS}

We calculated a regression line and the $95 \%$ predic- $-\stackrel{\circ}{\circ}$ tion limits of the right coronary artery and right ${ }_{0}$ coronary artery/aorta ratio with the general linear $\mathbb{W}^{\mathrm{N}}$ models (GLM) procedure in SAS User's Guide:O Statistics (Version 5 Edition, SAS Institute, North Carolina, 1985). Student's $t$ tests were performed to assess the differences in the right coronary artery $/ \stackrel{\infty}{\rightarrow}$ aorta ratio between groups.

We assessed the repeatability of a measurement from the means and standard deviations calculated $\stackrel{\mathbb{D}}{\odot}$ for intra-investigator and inter-investigator differ- $-\stackrel{\mathbb{D}}{\circ}$ ences. 
Distinguishing between anomalous origin of the left coronary artery from the pulmonary trunk

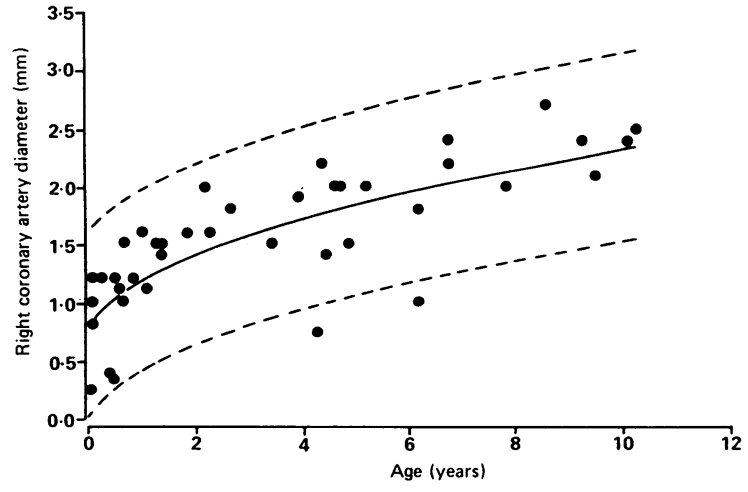

Fig 3 Normal right coronary artery diameters with age by echocardiographic measurement. The regression equation line and $95 \%$ prediction limits are given.

\section{Results}

\section{RESOLUTION BY PHANTOM MODEL STUDY}

When we used the zoom function of the equipment we were able to resolve two parallel lines of a USP size $2-0$ suture $(0.30-0.339 \mathrm{~mm}$ in diameter) with an absolute echo free space between the lines, but we could not resolve two lines for a USP size 0 suture $(0.20-0.249 \mathrm{~mm}$ in diameter). Therefore the resolution of this system must lie between 0.2 and $0.34 \mathrm{~mm}$. Theoretically, the leading edge method (arrow line $\mathbf{A}$ in fig 2) is more accurate for the assessment of vessel diameter; however, in the clinical setting scattered echoes from the surrounding tissue interfere with clear identification of the upper leading edge. For this reason we used the internal dimension of the coronary artery image (arrow line B in fig 2). This method therefore must underestimate the true diameter by $0.2-0.34 \mathrm{~mm}$.

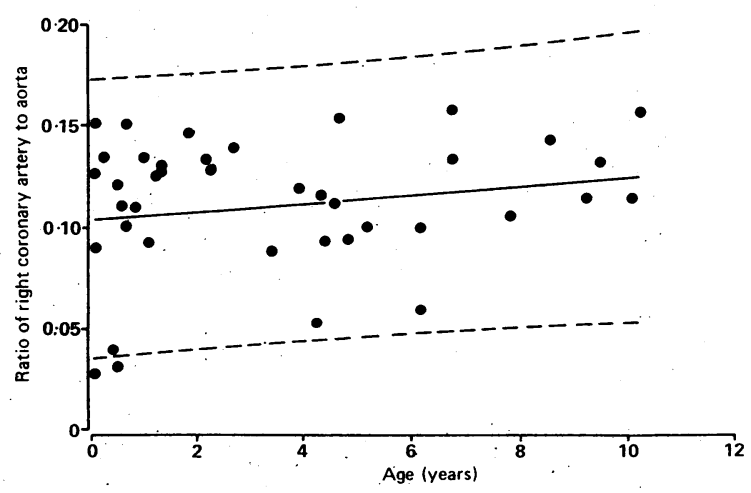

Fig 4 Ratio of right coronary artery to aorta with age by echocardiographic measurement in controls. The mean and 95\% prediction limits are given.
Table 4 Normal values of right coronary artery diameter and ratio of right coronary artery to aorta with age

\begin{tabular}{llllll}
\hline & \multicolumn{2}{l}{$R C A(\mathrm{~mm})$} & \multicolumn{2}{l}{$R C A / A O$} \\
\cline { 2 - 3 } \cline { 5 - 5 } Age & Mean & $95 \%$ upper limit & & Mean & $95 \%$ upper limit \\
\hline 1 mnth & 0.8 & 1.6 & 0.11 & 0.17 \\
2 mnth & 0.9 & 1.7 & 0.11 & 0.17 \\
3 mnth & 1.0 & 1.8 & 0.11 & 0.17 \\
6 mnth & 1.1 & 1.9 & 0.11 & 0.17 \\
1 yr & 1.2 & 2.0 & 0.12 & 0.18 \\
2 yr & 1.4 & 2.2 & 0.12 & 0.18 \\
3 yr & 1.6 & 2.4 & 0.12 & 0.18 \\
4 yr & 1.8 & 2.6 & 0.12 & 0.18 \\
6 yr & 1.9 & 2.7 & 0.12 & 0.19 \\
8 yr & 2.2 & 3.0 & 0.12 & 0.19 \\
10 yr & 2.5 & 3.2 & 0.13 & 0.20 \\
\hline
\end{tabular}

NORMAL RIGHT CORONARY ARTERY DIAMETER

Several linear regression models were fitted for the effect of age and various transformations of age (including $\log$ and square root of age) on right coronary artery diameter. The best fit was that between the square root of age and right coronary artery diameter ( $p=0.0001 . \mathbf{R}^{2}=0.62$ ) (fig 3).

Right coronary artery $(\mathrm{mm})=0.692+0.151 \sqrt{ }($ age in months), standard error for the estimated slope coefficient $=0.019$

Figure 3 gives prediction limits for the normal right coronary arteries. There was no evidence of an age effect on the right coronary artery/aorta ratio ( $p=0.21, \mathbf{R}^{2}=0.04$ ) (fig 4): right coronary artery/ aorta ratio $=0.104+0.00018$ (age in months), standard error for the estimated slope coefficient $=0.00014$. Table 4 lists the calculated means and 95\% upper limits of prediction for right coronary artery diameter and right coronary artery/ aorta ratio for individual ages.

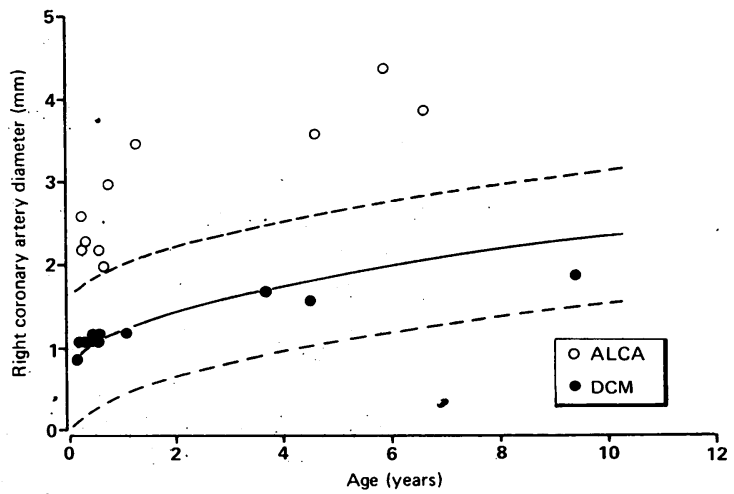

Fig 5. Right coronary artery diameter with age in dilated cardiomyopathy (DCM) and anomalous origin of the left coronary artery from the pulmonary trunk ( $A L C A)$ by echocardiographic measurement. The $95 \%$ prediction limits of normal are given. 
196

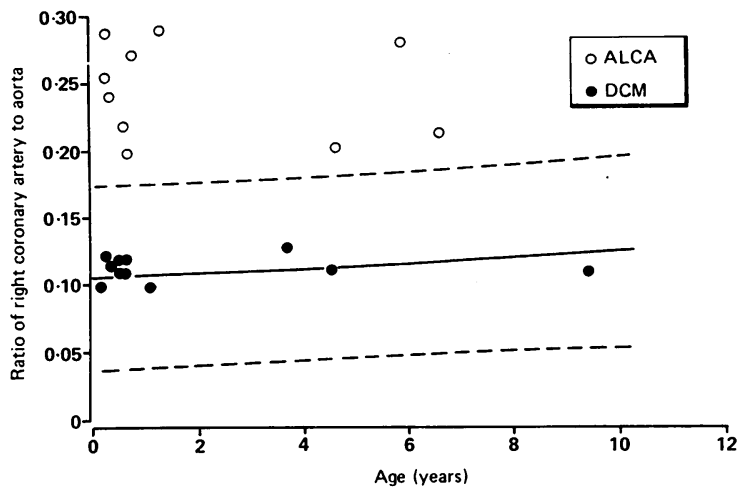

Fig 6 Ratio of right coronary artery to aorta with age in dilated cardiomyopathy (DCM) and anomalous origin of the left coronary artery from the pulmonary trunk $(A L C A)$ by echocardiographic measurement. The mean and $95 \%$ prediction limits of normal are given.

\section{DILATED CARDIOMYOPATHY}

The right coronary artery and right coronary artery/ aorta ratio were all within the normal range in patients with dilated cardiomyopathy (figs 5 and 6). The right coronary artery/aorta ratio ranged from $0 \cdot 10-0.13$ (mean (SD) 0.11 (0.009)).

\section{ANOMALOUS ORIGIN OF THE LEFT CORONARY ARTERY FROM THE PULMONARY TRUNK}

Direct imaging of the anomalous left coronary artery as it arose from the pulmonary trunk was only possible in five of 10 patients.

The size of the right coronary artery and the right coronary artery/aorta ratio were above the normal range in all patients with anomalous origin of the left coronary artery from the pulmonary trunk (figs 5 and 6). The right coronary artery/aorta ratio ranged from 0.21 to 0.29 with a mean (SD) $0.25(0.034)$ that was significantly greater than that in controls and in patients with a dilated cardiomyopathy ( $p<0.001$ ).

\section{INTRA AND INTER OBSERVER VARIABILITY OF MEASUREMENT}

The mean difference between measurements made by the same investigator was $0.0183(S D=0.153$, range -0.25 to 0.50 , SE of a single observation $0.019 \mathrm{~mm}$ ) for the right coronary artery, and 0.040 (SD 0.295 , range -0.60 to -0.70 , SE of a single observation $0.040 \mathrm{~mm}$ ) for the aorta.

The mean difference between measurements by the two investigators was 0.044 (SD 0.148 , range -0.18 to $0.40, \mathrm{SE}$ of a single observation $0.024 \mathrm{~mm}$ ) for the right coronary artery and -0.10 (SD 0.296, range -0.70 to $0.30, \mathrm{SE}$ of a single observation $0.050 \mathrm{~mm}$ ) for the aorta.

\section{Discussion}

DIFFICULTIES IN DISTINGUISHING BETWEEN ANOMALOUS ORIGIN OF THE LEFT CORONARY ARTERY FROM THE PULMONARY TRUNK AND OTHER FORMS OF DILATED CARDIOMYOPATHY Anomalous origin of the left coronary artery from the pulmonary trunk in infants and children is oftenis associated with a dilated cardiomyopathy because the $-\vec{\circ}$ collateral circulation from the right coronary artery isinadequate. ${ }^{1011}$ Early definitive diagnosis was basedw exclusively on aortography because clinical findings $?$ and ancillary investigations including chest $x$ ray electrocardiogram, ${ }^{89}$ nuclear myocardial scintigra-o phy, ${ }^{12}$ and analyses of left ventricular regional wall motion $^{13}$ did not distinguish this lesion from otherv forms of infantile dilated cardiomyopathy.

Fisher et al reported the first successful direct? visualisation of the anomalous origin of the left $\vec{T}$ coronary artery from the pulmonary trunk by cross sectional echocardiography in 1981.5 This noninvasive test is much safer than aortography. This is a great advantage because anomalous origin of the left coronary artery from the pulmonary trunk is mucho rarer than other forms of dilated cardiomyopathy..$^{10}$ Although the sensitivity of direct imaging of theo anomalous left coronary artery was thought to be adequate, false negative results have subsequentlyo been reported. ${ }^{67}$ In particular, it has been difficult too distinguish between the transverse sinus of the pericardium and the proximal portion of the left $\overrightarrow{\underline{\sigma}}$ coronary artery. We believe that echocardiographic visualisation of the origin of the anomalous left? coronary artery from the pulmonary trunk is stili difficult even when the anomaly is strongly suspected because a child has a dilated poorly contractile left ventricle.

\section{VALUE OF RIGHT CORONARY ARTERY} VISUALISATION AND MEASUREMENT IN DIAGNOSING ANOMALOUS ORIGIN OF THE LEFT CORONARY ARTERY FROM THE PULMONARY TRUNK

The presence of a tortuous dilated right coronaryn artery in anomalous origin of the left coronary artery from the pulmonary trunk is well known. ${ }^{89}$ It is $\mathrm{O}$ apparent from this study that either a directw measurement of the right coronary artery or right coronary artery/aorta ratio can be used to distinguisho between those patients with anomalous origin of the left coronary artery from the pulmonary trunk and ${ }^{\text {? }}$ other forms of dilated cardiomyopathy. Patients with anomalous origin of the left coronary artery from the pulmonary trunk always had values greater than the $95 \%$ upper limits of prediction. In our series the sensitivity and specificity was $100 \%$. 
This approach will miss only those rare cases who have pulmonary hypertension secondary to an associated intracardiac defect. These patients, however, should have normal left ventricular function, because coronary artery flow is preserved. ${ }^{14} 15$ This technique will also identify patients with other diseases associated with a large right coronary artery-such as right coronary arteriovenous fistula, single right coronary artery, Kawasaki disease, or congenital cardiac anomalies with severe right ventricular hypertrophy. We hope that such cardiac causes will be excluded by clinical and echocardiographic examinations.

We are aware of the potential difficulties in obtaining accurate measurements of the right coronary artery diameter through echocardiographic imaging. With experience, however, the method is being successfully applied to normal children and those with Kawasaki disease. ${ }^{16}$ At present we believe that all patients with an echocardiographic diagnosis of anomalous origin of the left coronary artery from the pulmonary trunk should have aortography.

\section{References}

1. Keith JD. The anomalous origin of the left coronary artery from the pulmonary artery. Br Heart $J$ 1959;21:149-61.

2 Driscoll DL, Nihill MR, Mullins CE, Cooley DA, McNamara DA. Management of symptomatic infants with anomalous origin of the left coronary artery from the pulmonary artery. Am J Cardiol 1981;47:642-8.

3 Arciniegas E, Farooki ZQ, Makimi M, Green EW. Management of anomalous left coronary artery from the pulmonary artery. Circulation 1980;62(suppl II):1-180-9.

4 Midgley FM, Watson DC Jr, Scott LP, et al. Repair of anomalous origin of the left coronary artery in the infant and small child. J Am Coll Cardiol 1984;4: $1231-4$.

5 Fisher EA, Sepehri B, Lendrum B, Luken J, Levitsky S. Two-dimensional echocardiographic visualization of the left coronary artery in anomalous origin of the left coronary artery from the pulmonary artery. Pre- and postoperative studies. Circulation 1981;63: 698-704.

6 Caldwell RL, Hurwitz RA, Girod DA, Weyman AE, Feigenbaum $H$. Two dimensional echocardiographic differentiation of anomalous left coronary artery from congestive cardiomyopathy. Am Heart J 1983; 106:710-6.

7 Robinson PJ, Sullivan ID, Kumpeng V, Anderson RH, Macartney FJ. Anomalous origin of the left coronary artery from the pulmonary trunk. Potential for false negative diagnosis with cross sectional echocardiography. Br Heart $J$ 1984;52:272-7.

8 Wesselhoeft H, Fawcett JS, Johnson AL. Anomalous origin of the left coronary artery from the pulmonary trunk. Its clinical spectrum, pathology, and pathophysiology, based on a review of 140 cases with seven further cases. Circulation 1968;38:403-25.

9 Askenazi J, Nadas AS. Anomalous left coronary artery originating from the pulmonary artery. Report on 15 cases. Circulation 1975;51:976-87.

10 Edwards JE. The direction of blood flow in coronary arteries arising from the pulmonary trunk. Circulation 1964;29:163-6.

11 Neufeld HN, Schneeweiss A. Coronary artery disease in infancy and children. Philadelphia: Lea and Febiger, 1983:1-30.

12 Gutgesel HP, Pinsky WW, DePuey EG. Thallium-201 myocardial perfusion imaging in infants and children. Value in distinguishing anomalous left coronary artery from congestive cardiomyopathy. Circulation 1980; 61:596-9.

13 Rein AJJT, Colan SD, Parness IR, Sanders SP. Regional and global left ventricular function in infants with anomalous origin of the left coronary artery from the pulmonary trunk: preoperative and postoperative assessment: Circulation 1987;75:115-23.

14 Pinsky WW, Gillette PC, Duff DF, et al. Anomalous origin of left coronary artery from the pulmonary artery with ventricular septal defect. Circulation 1978;57:1026-30.

15 Cottrill CM, Davis D, McMillen M, O’Connor WN, Noonan JA, Todd EP. Anomalous left coronary artery from the pulmonary artery: significance of associated intracardiac defects. J Am Coll Cardiol 1985;6:237-42.

16 Arjunan K, Daniels SR, Meyer RA, Schwaltz DC, Barron $H$, Kaplan S. Coronary artery caliber in normal children and patients with Kawasaki disease but without aneurysm: an echocardiographic and angiographic study. J Am Coll Cardiol 1986;8: 1119-24. 